\title{
CENAS ESCOLARES ENTRE A NEGAÇÃO DA DIFERENÇA E A DISCIPLINARIZAÇÃO DOS CORPOS: UMA ANÁLISE FOUCAULTIANA DAS RELAÇÕES ESCOLARES
}

\author{
SCHOOL SCENES BETWEEN THE DENIAL OF DIFFERENCE AND THE DISCIPLINING OF \\ BODIES: A FOUCAULT ANALYSIS OF SCHOOL RELATIONS
}

\author{
https://orcid.org/0000-0003-4871-4769 Rachel Pulcino ${ }^{\mathrm{A}}$ \\ https://orcid.org/0000-0002-9555-2099 Pâmela Esteves ${ }^{B}$ \\ ${ }^{\text {A }}$ Pontifícia Universidade Católica do Rio de Janeiro (PUC-Rio), Rio de Janeiro, RJ, Brasil \\ ${ }^{\text {B }}$ Universidade do Estado do Rio de Janeiro (Uerj), Rio de Janeiro, RJ, Brasil \\ Recebido em: 24 abr. 2020 | Aceito em: 14 ag. 2020 \\ Correspondência: Rachel Pulcino (rachelpulcino@gmail..com)
}

\begin{abstract}
Resumo
O conflito, a diferença e a disciplinarização dos corpos são temas deste artigo. Percorremos, seguindo uma inspiração foucaultiana, duas cenas escolares que retratam situações de conflitos no espaço escolar. Nossas cenas foram coletadas em duas escolas públicas situadas na zona sul da cidade do Rio de Janeiro. Na primeira cena, analisamos a reação e a fala da equipe de gestão da escola ao receberem uma proposta de pesquisa. E, na segunda, interpretamos uma situação de conflito que tem como protagonistas principais um aluno identificado como homossexual, e um inspetor. Com essas cenas, nos propomos a pensar as relações e as produções de subjetividades no espaço escolar, a partir do referencial foucaultiano.
\end{abstract}

Palavras-chave: disciplinarização dos corpos; diferenças; conflitos; escola.

\begin{abstract}
The conflict, the difference and the disciplining of the bodies are themes of this article. We followed, following Foucauldian inspiration, two school scenes that portray conflict situations in the school space. Our scenes were collected in two public schools located in the south zone of the city of Rio de Janeiro. In the first scene, we analyzed the reaction and the speech of the school management team, when they received a research proposal. And, in the second, we interpret a conflict situation whose main protagonists are a student identified as homosexual, and the inspector. With these scenes, we propose to think about the relations and the production of subjectivities in the school space, based on the Foucaultian framework.
\end{abstract}

Keywords: disciplining bodies; differences; conflicts; school. 


\section{Um convite à problematização}

Esse texto é um convite! Um convite à compreensão da instituição escolar, e ao mesmo tempo, uma tentativa de desnaturalizar a universalidade e a eternidade desta. O objetivo é pensar a escola como uma instituição inserida em um contexto histórico específico, estruturada a partir de funções sociais singulares e imersa em um projeto político estatal particular, endossado pelo sistema capitalista de produção.

De antemão, é preciso assinalar, que aceitar esse convite significa estar disposto a compreender que a escola não é universal e muito menos eterna. Enquanto instituição socializadora, pública, gratuita e obrigatória, a escola é recente, com menos de dois séculos de existência. Compreender a escola a partir do viés da desnaturalização significa buscar um olhar arqueológico no sentido foucaultiano, investigar as disputar de poder e os projetos políticos que estiveram nas bases de sua construção, formando assim, um sistema de escolarização.

Trata-se de pensar a escola como uma maquinaria, um dispositivo de poder e normas disciplinares que ocupou e permanece ocupando o tempo e o espaço de crianças e adolescentes por pelo menos 10 anos. Por que usar o termo maquinaria? Porque a escola foi estruturada como um mecanismo biopolítico de governamentabilidade da infância, um sistema de produção e regulamentação de modos de viver e se comportar. É por esse viés interpretativo que esse texto busca sustentar a arqueologia do sistema escolar como uma maquinaria regulamentadora da condição de ser criança e adolescente. Todavia, há uma ressalva a ser considerada, não se trata de todas as infâncias, aqui estamos considerando a escola nacional, aquela instituída para disciplinar os corpos das infâncias pobres, negras e desfavorecidas. As outras infâncias pertencentes a elite, eram e continuam sendo enviadas à outras instituições de ensino (liceus e colégios especializados), cujos processos de ensino, ainda que regulamentadores e disciplinadores das infâncias são múltiplos e direcionados para o talento e aptidão de cada indivíduo. (VARELA; ALVAREZ-URIA, 1991, p. 66)

Um olhar arqueológico sobre o século XX nos possibilita identificar quatro princípios que foram discursivamente e legalmente instituídos para consolidação dos sistemas de escolarização das escolas nacionais: (1) um estatuto da infância foi definido, a criança passou a ser vista como uma instituição social, e educá-la passou a ser uma tarefa do Estado (ARIÈS, 1978). Várias infâncias foram criadas a partir de critérios socioeconômicos, e a educação escolar se transformou em um dispositivo de naturalização de uma sociedade de classes ao instrumentalizar a existências de infâncias rudes (classes populares) e infâncias de qualidade (classes abastadas). A escola nasceu, assim, como uma instituição legitimadora e reprodutora 
da desigualdade social e de controle das infâncias, já que os estatutos da infância elaborados tanto na Europa quanto na América caracterizavam a infância como maleável, capaz de ser modelada, débil e por isso necessitando ser tutelada, rude e incivilizada e daí decorre a justificativa para a normatização e disciplinarização dos corpos infantis. (VARELA; ALVAREZ-URIA, 1991).

Além da elaboração de um estatuto específico para infância, o sistema de escolarização contemplou (2) um espaço específico destinado à educação das infâncias (3) a emergência de um grupo de especialistas dotados de conhecimentos específicos do universo infantil e (4) o enfraquecimento de outras formas de socialização/educação, como, por exemplo, o reduzido papel deixado às família, já que a escola foi institucionalizada como obrigatória, decretada pelos poderes públicos e sancionada pela legislação vigente.

Nesse sentido, um olhar arqueológico sobre a instituição escolar nos permite compreender a origem da escola a partir de uma perspectiva problematizadora e investigativa, compreendendo as funções sociais, políticas e econômicas que estiveram nas engrenagens da formação da maquinaria escolar, e principalmente escavando os discursos de poder que distorcem e camuflam as diversas formas de regulamentação justificadas sob a égide de uma suposta "Ciência Pedagógica".

É a partir desse olhar de desnaturalização/problematização que esse texto tem como objetivo compreender os diferentes componentes da construção do clima escolar, no que tange às relações intersubjetivas que constituem os processos de socialização. Essa compreensão direciona-se, em um primeiro momento, para investigação dos conceitos de indisciplinas, conflitos e violências que, na contemporaneidade, se configuraram em marcas singulares do cotidiano educacional. Nossa intenção é problematizar como essas marcas singulares influenciam o clima escolar, entendendo este conceito como um conjunto de ações e expectativas recíprocas compartilhadas pelos sujeitos em um ambiente institucional. Uma escola onde as relações entre os diferentes membros da comunidade educacional são positivas favorece um bom clima de trabalho, resultando, assim, em processos favoráveis ao conhecimento pedagógico, não se limitando exclusivamente ao rendimento acadêmico. Como enfatizam Cunha e Costa, (2009, p. 12 e 13):

O clima de uma escola resulta do tipo de programa, dos processos utilizados, das condições ambientes que caracterizam a escola como uma instituição e como um agrupamento de alunos, dos departamentos, do pessoal e dos membros da direção. Cada escola possui o seu clima próprio. O clima determina a qualidade de vida e a produtividade dos docentes e dos alunos. O clima é um fator crítico para a saúde e para a eficácia de uma escola. 
Expostas as bases teóricas e analíticas que fundamentam a construção deste ensaio, torna-se necessária expor como essa escrita está organizada em cinco pontos, sendo o primeiro esta introdução. Em seguida, apresentamos o percurso metodológico, expondo os caminhos percorridos para a seleção e recorte das situações de conflito tratadas no texto. O terceiro e o quarto ponto, tratam especificamente dos cenários analisados: (i) a cena um, problematiza a fala de uma diretora escolar durante uma reunião; (ii) a cena dois, discute uma situação de conflito que se transformou em violência escolar que tem entre seus personagens um estudante homossexual. E, por fim, propomos uma guisa conclusiva buscando encontrar as interseções entre as duas cenas, no intento de refletir sobre os processos e mecanismos de reprodução do ideal normativo e regulatório das relações de poder que ainda são recorrentes no espaço escolar.

\section{Caminhos metodológicos}

As cenas escolares tratadas nesse ensaio foram coletadas durante a realização de uma pesquisa interinstitucional ${ }^{\mathrm{i}}$, em escolas públicas da rede municipal do Rio de Janeiro.

A gente foi percebendo que, os preconceitos e a discriminação são um problema para a escola, são um problema social, e que inevitavelmente, porque se essa escola está nessa sociedade e não em outra sociedade, a escola brasileira enfrenta isso no seu cotidiano. (ANDRADE, 2016, p. 2)

Tratava-se de uma pesquisa de abordagem quantitativa e qualitativa, sendo as cenas analisadas identificadas e transcritas durante o período de aplicação de questionários. A pesquisa tinha como objetivo identificar como as práticas de preconceito, discriminação e cotidianos escolares marcados por conflitos poderiam causar impactos na trajetória escolar e na aprendizagem dos estudantes. Para isso, constava no escopo da pesquisa a realização de questionários, com estudantes do $7^{\circ}$ ano do ensino fundamental II da rede municipal carioca. O contato com as escolas seguiu sob duas formas: (1) aproximação com as escolas identificadas com o Projeto Parceria, vinculadas à instituição PUC-Rio, assumindo a liderança na condução da pesquisa; (2) entrada via indicação por parte Coordenadoria Regional de Educação ( $\left.2^{\circ} \mathrm{CRE}\right)$, uma vez que a pesquisa tinha como recorte a investigação de escolas localizadas na região da zona sul do Rio de Janeiro, chegamos ao número de 10 escolas municipais integradas ao projeto, sendo estas situadas nos seguintes bairros as proximidades da 
PUC-Rio: Gávea, Jardim Botânico, Leblon, Ipanema, Copacabana, Humaitá e Botafogo. Concluídas as etapas de contato com as escolas, a pesquisa iniciou a fase de trabalho de campo, mediantes as rotinas de marcação, agendamento para as aplicações dos questionários com as equipes diretivas e de coordenação das escolas. Após a etapa de questionários, a pesquisa contava ainda com uma fase de entrevistas a serem realizadas com docentes e discentes das instituições escolares investigadas.

Para compreender, os diálogos e as cenas narradas a seguir, vale entender um pouco do questionário. Este fora construído seguindo modelo de Escala de Likert, e tinha como objetivo tratar de temáticas ligadas a diversidade e ao preconceito, possuindo os seguintes eixos: (1) gênero e sexualidades; (2) racismo; (3) intolerância religiosa; (4) deficiências; (5) bullying. $O$ questionário contava ainda com o conjunto de questões destinadas a análise do perfil socioeconômico dos estudantes das escolas. Seguindo o modelo de Likert, o questionário trazia frases afirmativas e solicitava aos estudantes que respondessem a elas - as frases -, partindo de uma gradação entre: discordo muito; discordo; concordo; e, concordo muito. Sendo assim, o objetivo era medir o grau de concordância e/ou discordância dos sujeitos referentes às frases. Sobre as frases, elas tinham como objetivo retratar percepções e falas pejorativas e preconceituosas que povoam imaginário coletivo. Assim, ao longo das aplicações, percebemos que havia uma riqueza presente para além dos dados respondidos que estavam nos diálogos, nas conversas entre estudantes sobre as frases do questionário e na forma como eles, interpretavam e debatiam elas.

Os relatos que integram as cenas dizem desses diálogos travados durante a aplicação do questionário. Para este ensaio, selecionamos cenas distintas, cada uma delas, releva um episódio diferente que marcou nossa entrada nas escolas que integravam a pesquisa. São duas cenas, duas histórias que emergiram da experiência do campo. "A experiência é o que nos passa, o que nos acontece, o que nos toca" (BONDIA, 2002, p. 21). Os relatos colhidos e analisados nas próximas páginas desse ensaio, apontam para situações que marcaram nossa experiência no campo, a partir das possiblidades que delas abrimos de refletir sobre a escola enquanto instância normalizadora e disciplinadora das relações e dos sujeitos.

Elas - as cenas - sinalizam para a forma como as escolas e os membros de suas equipes entendem a diversidade que habita a escola, mas também das possibilidades de ser/estar dos estudantes, assim como dos modos de subjetivação que envolve os gêneros e as sexualidades.

\section{Cena um: a negação e o "problema” da diferença}


Em uma escola da pesquisa, localizada no bairro da Gávea, ouvimos a seguinte fala da diretora: "A gente não tem esse tipo de problema aqui." (Diretora, 2016) ${ }^{\mathrm{ii}}$. Essa frase foi dita durante uma reunião em que apresentávamos a pesquisa. Quando chegamos à escola, a diretora ainda não estava presente e começamos nossa conversa com a vice-diretora. Ela não demonstrava nem aceitação, nem negação da pesquisa e dizia constantemente que podíamos conversar, mas que a decisão final era da diretora.

Quando a diretora chegou explicamos a temática da pesquisa, ou seja, informamos que a pesquisa tinha como objetivo tratar de temas referentes a preconceitos e discriminações e que gostaríamos de aplicar inicialmente, questionários com as turmas do $7^{0}$ ano do ensino fundamental. Explicamos a trajetória do grupo de pesquisa, com projetos relacionados a essas questões e ouvimos da diretora como resposta, a frase: “A gente não tem esse tipo de problema aqui”.

Naquele momento, percebemos que a diretora percebia a pesquisa como uma ameaça. Um medo envolvia sua fala, como se a pesquisa ao tocar em temas ligados a diversidade pudesse acordar situações que estavam adormecidas. Durante a conversa, ela nos cortava, dizendo que não tinham esse problema na escola, dizia que conhecia o trabalho da PUC-Rio, que já tiveram outras pesquisas acontecendo na escola, mas que não tinha certeza se queria a nossa. Em vários momentos a palavra "problema" retornava, como se o problema em si, fosse à diferença, como se a diferença conduzisse o problema e não o preconceito e a intolerância no tratamento com os diferentes.

A necessidade de negar a presença do preconceito na escola aponta para uma dificuldade por parte da direção em reconhecer a escola como lócus de discussão. Ela sinaliza ainda, uma necessidade de marcar aquele contexto como livre de "problemas". Ao mesmo tempo, sua negação em participar da pesquisa, em não aceitar a entrada de uma pesquisa destinada a tratar da diversidade e dos preconceitos que rondam esses temas, a diretora silencia o debate e age como se tivesse medo do tema. Um medo marcado por uma negativa, um medo que parece aos nossos olhos, estar pautado numa visão disciplinar da escola, compreendendo a possibilidade de debate entre estudantes, a partir da pesquisa como algo que poderia acabar com a aparente "normalidade" das relações presente na escola, como se a pesquisa fosse trazer a tona o "problema" silenciado e negado no espaço escolar. É claro que nenhuma escola, precisa aceitar uma pesquisa, mas nossa reflexão aponta sobre o como essa negativa é justificada. E, essa justificativa aponta uma postura normalizadora e disciplinadora das relações. 
A escola enquanto uma instituição disciplinar normaliza as relações, condicionando os sujeitos que integram o espaço a processo de homogeneização, e ao mesmo tempo, resguarda a individualidade sendo esta utilizada para manutenção do poder disciplinar. "É um controle normalizante, uma vigilância que permite qualificar, classificar e punir. Estabelece sobre os indivíduos uma visibilidade através da qual são diferenciados e sancionados" (FOUCAULT, 2014, p. 181). Assim, o ato de negar a pesquisa, através da justificativa concedida pela equipe da direção indica uma silenciamento da diversidade ancorado numa visão disciplinar das relações na escola. A negação da diversidade no espaço escolar indica uma percepção homogeneizadora das relações, pois ela se baseia na ideia de que a partir do encontro com o tema, possíveis problemas poderiam vir a existir, quando o que entendemos é que a discussão sobre a diversidade na escola, contribui para a redução do preconceito que ocorre de modo velado e escondido nos espaços escolares.

As falas da diretora e da vice-diretora passavam uma visão de que abordar as diferenças, ou seja, tornar essas questões visíveis através da sua nomeação poderia trazer preconceitos para a escola. Como se essas diferenças já não habitassem o cotidiano da escola, dessa e de muitas outras em nossa cidade. Suas falas expressam uma visão frequente nas escolas que apontam para o silenciamento e negação da diversidade que habita o espaço escolar.

(...) termo "diferença", nos depoimentos dos educadores, é frequentemente associado a um problema a ser resolvido, à deficiência, ao déficit cultural e à desigualdade. (...) Enfim, os diferentes são um problema que a escola e os educadores têm de enfrentar, e esta situação vem se agravando e não sabemos como lidar com ela. Esta é a tônica que predomina nos relatos dos educadores. Somente em poucos depoimentos a diferença é articulada a identidades plurais que enriquecem os processos pedagógicos e devem ser reconhecidas e valorizadas (CANDAU, 2012, p. 239).

Além dessa ocultação, gostaríamos de chamar atenção para o termo "problema”. Ao apresentar a temática da pesquisa, falávamos da diversidade e que nosso intuito era entender como as estudantes pensavam sobre esses assuntos. Explicávamos que o questionário era composto de falas e expressões presentes em nosso cotidiano e que nosso objetivo era entender como eles (estudantes) se colocavam diante dessas falas. Ou seja, nós não usávamos a palavra problema para nos referir à diversidade. A palavra surge da Diretora para justificar o fato de não querer a pesquisa na escola.

A diferença é problema? Ou, ela quando ocultada, negada, silenciada se transforma em uma problemática que explode no ambiente escolar? Desse modo, se o contexto impõe uma padronização e uniformização dos sujeitos, aqueles que são diferentes, ficam cada vez mais 
deslocadas e tem sua diferença marcada e colocada em evidência. Não como uma possibilidade de construção de novas subjetividades, mas como um problema a ser sanado e resolvido.

Vivemos num espaço e num tempo marcados pela efervescência das questões trazidas pela diferença. Diferenças de classe social, de gênero, de raça, de orientação sexual, de crenças religiosas, de origens, de pertencimentos, de geração e etc. (...) Diferença que durante muito tempo foi calada devido a um discurso que, equivocadamente, tomou a desigualdade como uniformidade. Com exceção da diferença de classe social, as demais questões identitárias e culturais são relativamente novas, emergiram nas últimas décadas, tanto no campo das ciências sociais quanto na reflexão educacional (ANDRADE; CÂMARA, 2015, p. 13).

Isso significa dizer que até pouco tempo atrás, a "regra" era tratar a todas como iguais, escondendo e, com isso, silenciando essas diferenças. Porém, esse ocultamento só contribuiu para colocar a diversidade, principalmente aquelas que não se encaixavam e/ou se enquadravam no padrão estabelecido constantemente a margem das relações e processos sociais. Se esse movimento é recente, como fazer chegar as escolas e possibilitar outras leituras além do "problema”?

A própria noção de problema pode vir ser a questionada. Na conversa com a diretora parecia clara a sua intenção em não aceitar a pesquisa, mas não estava tão nítido qual seria o problema entorno da diversidade. Seria a diversidade em si um problema? $\mathrm{Ou}$, o problema seria a incapacidade, embora momentânea, dessa diretora em aceitar que as questões advindas da diversidade já povoavam a escola? Indo além, o problema seria a dificuldade dessa escola, a partir de suas agentes de lidarem com os desafios expostos pela diferença?

Essas questões não se encerram, nem podem ser respondidas nesse momento, mas elas lançam algumas pistas sobre como a diversidade é entendida no cotidiano das escolas. Partindo ainda desse diálogo, será que existem diferenças que são mais "problemáticas" do que outras?

O problema, ou a negação da diferença, afirmada pela diretora nos convida a pensar sobre as diferentes dimensões que constituem o processo de silenciamento. Ou seja, dizer que a diversidade é um problema e temer que falar sobre ela desperte tensões no cotidiano é negar que existem práticas, ações, discursos que constroem sujeitos em meio a processos de silenciamentos. Assim, a escola é uma dessas instâncias sociais que operam na ocultação das diferenças, seja através de discursos que reforçam a igualdade e a homogeneidade entre estudantes, seja na docilização de corpos. Na medida em que problematizamos essas falas e tencionamos lugares, daquilo que é visto como problema e apostamos na potencialidade da escola na construção de novas formas de lidar e entender as diferenças. Pensar os silêncios é olhar para as relações que estão sendo construídas no espaço escolar, nesse sentido: 
Os silêncios, então devem ser entendidos como produtivos, na medida em que permeiam as relações de força e de poder, produzem sujeitos, experiências, prazeres, saberes, discursos, práticas, instituições, enfim, dão origem a isso que chamamos de "realidade", ancorados nos seus rituais e objetos de verdade (FERRARI; MARQUES, 2011, p. 23).

Embora o silenciamento tenha nos chamado atenção, não podemos dizer que ele foi predominante em todas as escolas, demonstrando a diversidade de posturas no que diz respeito a aceitação da pesquisa, como se poderá perceber na próxima seção quando trazemos outra visita para a reflexão, expondo outro olhar sobre a possibilidade da pesquisa e do papel das pesquisadoras na escola.

\section{Cena dois: "eu converso muito com eles...” as homossexualidades e a disciplinarização dos corpos na escola}

Em outra escola, esta localizada no bairro do Leblon, conversamos com a vice-diretora, que se mostrou muito atenciosa e disponível, com quem tivemos o maior encontro, passando de mais de uma hora de duração. Foram quase 1h30min de conversa, sendo que desse tempo nós falamos muito pouco. Durante boa parte do tempo quem falou foi à vice-diretora. Ela contou que estava atuando nessa escola há muitos anos e que durante sua convivência com as estudantes, havia assumido uma posição de escuta e que nessa nova função, essa escuta tinha crescido. Assim, o diretor tomava conta da burocracia e agia na resolução de grandes questões e ela ficava encarregada desse cuidado do dia-a-dia.

Quando chegamos à escola, explicamos que a pesquisa tratava de temáticas ligadas a preconceitos e que pretendíamos realizar questionários com as estudantes. Pouco depois, ela nos contou que a escola tinha algumas questões relacionadas a essa temática e que havia um grupo de estudantes meninos que eram difíceis. Ela chegou a comentar seus nomes e disse que eles frequentemente causavam problemas, de maneira que foi estabelecida em sua fala a relação entre gênero, sexualidade e problema. Acabamos encontrando com tais alunos no dia da aplicação dos questionários. Ela inicialmente não especificou exatamente os "problemas" que esses meninos causavam, se limitando a classifica-los como "difíceis", indisciplinados e que eles (os meninos) gostavam de chamar atenção dentro da escola. A vice-diretora disse que além dela, havia outra pessoa que também escutava muito os estudantes - o inspetor - e que eles o reconheciam como uma figura acolhedora. Nós chegamos a conversar com ele anteriormente, uma vez que foi apontado como uma pessoa que tinha boa circulação entre os alunos. Porém no dia da aplicação dos questionários ele teve uma atitude um pouco "abrupta” em uma turma. Essa cena marcou a aplicação e é ela que será narrada e analisada. 
Nesse momento estávamos à frente da turma, na aplicação do questionário. A turma era falante, igual à maioria das turmas em que aplicamos os questionários. $\mathrm{O}$ aluno em questão era um menino gay e ele estava num grupo que sentava no fundo da sala e um dos mais falantes durante a aplicação. Essa cena aconteceu logo no início da aplicação. O inspetor veio do corredor gritando, chamando o estudante pelo nome, mandando-o se levantar e sair de sala. $\mathrm{O}$ menino respondeu dizendo que não estava fazendo nada. E efetivamente, naquele momento, desde nossa entrada em sala ele não tinha feito nada que pudesse ter causado tamanha reação. Entretanto, não sabemos o que aconteceu antes, mas essa cena nos marcou. Não sabíamos o que fazer diante daquele ato, nem o porquê daquela entrada ser feita de tal forma. Essa cena nos marcou pela sua violência. Era isso que para nós, agentes externos à escola que acompanhávamos a turma em sala, um tanto agitada, mas nada fora do padrão que havíamos encontrado até então.

Pouco depois dessa cena, percebemos que aquele aluno, era um dos estudantes de quem a vice-diretora havia falado em nosso primeiro encontro. E, por consequência, imaginamos que o grupo que estava sentado com ele no momento da aplicação seriam os outros estudantes mencionados pela diretora. A partir desse momento, muitas questões começaram a surgir: o que poderia ter acontecido de tão grave que mesmo diante de pessoas desconhecidas, um grupo de pesquisadores da universidade para o inspetor entrar na sala daquela forma? Seria essa cena apenas um espanto para nós? E, quanto ao estudante o que aconteceu antes?

O fato de não sabermos o que aconteceu antes dessa entrada abrupta do inspetor, limita nossas possibilidades de compreensão sobre a cena. Pois, não sabemos o que havia causado tanta urgência e que poderia ter mobilizado tanto o inspetor. Porém, ficamos com a cena presenciada por nós e ela nos parece forte.

Segundo a vice-diretora esse estudante era de um grupo que vivia causando conflitos na escola. Quais seriam esses conflitos? Sua homossexualidade seria alvo desses conflitos? Ou seja, o fato dele ser gay poderia causar problemas no convívio com as demais pessoas? Dito de outra forma, a homossexualidade ou a expressão dela no ambiente escolar seria um desafio à escola?

Segundo Ferrari (2011) as homossexualidades estão presentes no espaço escolar, seja nas salas de aula, materializadas na presença de estudantes e docentes, através dos assuntos e conteúdos. Entretanto, mesmo diante dessa presença a escola, enquanto instituição possui dificuldades em lidar com as subjetividades homossexuais. Essa dificuldade que perpassa a experiência de estudantes homossexuais na escola é o quanto as homossexualidades, são 
compreendidas ainda dentro do espaço escolar de modo essencializado, ou seja, como se existisse uma forma correta de ser homossexual. Essa essencialização pode ser um dos motivos que fazem a vice-diretora tratar o comportamento dos meninos como um problema, pois ela não conseguia inserir eles num quadro padronizado e disciplinado da homossexualidade. Sobre as homossexualidades na escola, Ferrari (2011, p. 95), identificou que há dentro das escolas um discurso que legitima um "tipo de homossexual aceitável", isso significa dizer que aqueles que não estão inseridos nesse padrão são entendidos como inaceitáveis ou desviantes, estando sujeitos a sanções e correções, por parte das instâncias disciplinadoras da escola.

O abjeto designa aqui precisamente aquelas zonas "inóspitas" e "inabitáveis" da vida social, que são, não obstante, densamente povoadas por aqueles que não gozam do status de sujeito, mas cujo habitar sob o signo do "inabitável" é necessário para que o domínio do sujeito seja circunscrito (BUTLER, 2000, p. 156).

A noção de abjeção descrita por Butler (2000) demarca o espaço e as possibilidades de construções possíveis para aqueles que excedem os limites das heterossexualidades. Seus corpos e suas performances são lidos e recebidos como afrontas à instituição, elas simbolizam o limite, da própria condição e da heteronormatividade. Entendemos por heteronormatividade um sistema que organiza os sexos e os gêneros, seguindo um ideal regulatório, limitando as possibilidades de ser e estar no mundo que promovam a desestabilização dos ordenamentos entre as noções de feminino e masculino. Há outra tensão que acompanha as homossexualidades na escola, a homofobia. Apesar desta cena não trazer explicitamente uma prática de homofobia, não podemos negar que a construção das homossexualidades via sistema de abjeção, como uma subjetividade desviante, demarca a sua existência pela negação, como alguém que vive no "não lugar". Logo, não podemos negar que a homofobia atua e se manifesta de diferentes formas, seja no discurso dos agentes escolares, na descrição do grupo "problemático" presente desde o nosso primeiro encontro com a vice-diretora na escola, como nas escolhas e formas de tratamentos que são designadas aos estudantes no espaço escolar. Entendemos homofobia como:

(...) um fenômeno social relacionado a preconceitos, discriminação e violência contra quaisquer sujeitos, expressões e estilos de vida que indiquem transgressão ou dissintonia em relação às normas de gênero, à matriz heterossexual, à heteronormatividade (JUNQUEIRA, 2013, p. 484).

Retomando as anotações do caderno de campo, encontramos que o menino retirado de sala pelo inspetor, juntamente com seu grupo, estava falando durante a aplicação do questionário, comentando as frases, fazendo brincadeiras e piadas, principalmente das frases que traziam temas de gênero ou sexualidade. Logo, o menino não apresentava um 
comportamento "adequado", ele não agia de forma "disciplinada", ele agia com liberdade, dentro de uma instituição historicamente destinada para disciplinar, homogeneizar e normalizar os corpos e os sujeitos. O menino, ao assumir sua homossexualidade e anuncia-la na escola, criava fissuras, rachaduras no sistema disciplinar.

“(...) ao retirar o aluno da sala, estabelece uma ruptura entre ele e a turma, entre as homossexualidades (corporificada no aluno homossexual) que foram evitadas e colocadas para fora de sala de aula e as heterossexualidades que permaneceram na sala e discutidas como práticas válidas e de que se podem falar" (FERRARI, 2011, p. 95).

Além do tratamento dado ao aluno homossexual, essa cena expõe uma contradição. Esse era o mesmo inspetor que a vice-diretora havia caracterizado como uma pessoa cuidadora e com um relacionamento atencioso com os estudantes. Porém, o episódio que assistimos evidencia uma atitude violenta no trato com o estudante. Isso nos faz refletir sobre a dimensão de cuidado que está explícita no discurso da vice-diretora. Seria a correção, pela via de uma demonstração de força e controle uma atitude de cuidado? Ou ainda, será que todos merecem/recebem a mesma forma de cuidado? Que relações foram construídas no cotidiano dessa escola que possibilitaram que um ato que expressa à violência fosse lido como comum pelos seus agentes?

A escola é segundo Foucault (2014b) uma das instituições de sequestro, que no mundo moderno/contemporâneo têm como finalidade sequestrar as singularidades identitárias através da domesticação e disciplinarização dos corpos. Esse processo de disciplinarização é praticado no espaço escolar através da homogeneização dos sujeitos; organização do tempo em horas de aulas; divisão dos indivíduos por idade e série de ensino; construção das classes e/ou turmas; e, dos exames repartidos entre diferentes avaliações. Todos esses elementos compõe um quadro de disciplinarização dos corpos, ensinando as estudantes que há uma forma específica de agir no ambiente educacional. O cuidado anunciado pela vice-diretora em nosso primeiro encontro é manifestado em forma de poder disciplinar, pelo inspetor ao retirar o estudante de sala. $\mathrm{O}$ grito, a entrada durante a atividade, a retirada de sala, são partes desse exercício disciplinar:

(...) a tática disciplinar se situa sobre o eixo que ligar o singular e o múltiplo. Ela permite ao mesmo tempo a caracterização do indivíduo como indivíduo, e a colocação em ordem de uma multiplicidade dada. Ela é a condição primeira para o controle e o uso de um conjunto de elementos distintos: a base para uma microfísica de um poder que poderíamos chamar de "celular" (FOUCAULT, 2014b., p. 146).

A própria noção de cuidado apresentada pela vice-diretora precisa ser analisada. Retomando nossa conversa, ela afirmava que seu papel na escola era cuidar das questões do cotidiano da escola e que ela muitas vezes assumia um lugar de escuta. Durante nossa conversa 
ela comentava que a escola tinha muitas questões, que recebia estudantes oriundos de transferências, "aqueles que causavam problemas" em outras escolas da região. E que ela se colocava para esses sujeitos como uma pessoa que estava disponível. Porém, a cena que assistimos trazia outro dado, ou talvez outra face desse cuidado, aquele que é encenado pelo controle, pela sanção disciplinar. Mais uma vez, não podemos aqui julgar se ação foi excessiva ou não, pois não sabemos o que ocorreu antes, temos apenas essa cena.

A atitude do inspetor é uma dessas formas pela qual a escola age por meio da disciplina, da correção e controle. Tirar um aluno de sala, entrar na sala gritando, mesmo diante de um grupo de agentes externos a escola diz sobre como as relações são vivenciadas naquele ambiente, diz que o grito é uma forma de correção, revela que há momentos em que não existe espaço para o diálogo. Pois, quando o menino tentou argumentar que estava quieto, ele não foi ouvido e tampouco ouviu uma justificativa, um anúncio sobre o porquê estava sendo tratado daquela forma; naquele momento, ele deveria apenas obedecer.

O episódio que presenciamos é parte do exercício de disciplinar os corpos dentro da estrutura escolar. Aquela cena concedia sentido uma série de atividades que constroem e constituem a escola como uma instância disciplinadora.

A disciplina "fabrica" indivíduos; ela é a técnica específica de um poder que toma os indivíduos ao mesmo tempo como objetos e como instrumentos de seu exercício. Não é um poder triunfante que, a partir de seu próprio excesso, pode-se fiar em seu poderio; é um poder modesto, desconfiado, que funciona a modo de uma economia calculada, mas permanente. (...) O sucesso do poder disciplinar se deve sem dúvida ao uso de instrumentos simples: o olhar hierárquico, a sanção normalizadora e sua combinação num procedimento que lhe é específico, o exame (FOUCAULT, 2014b., p. 167).

Presenciamos, através dessa cena, como o discurso sobre esse menino, tornava-se realidade, a partir da ação disciplinadora do inspetor: "o menino problema”, ou seja, o indivíduo perigoso, aquele que devemos manter sob vigilância e controle; e o inspetor, representante da coerção, da disciplina, aquele que investido do poder que representa e do discurso que por ele se constrói, tem o papel de conduzir o indivíduo perigoso para o seu exame. (FOUCAULT, 2014a; 2014b). Dessa forma, o cuidado anunciado pela vice-diretora em nossa primeira visita a escola é praticado pela via da disciplinarização dos corpos, do "adestramento" dos estudantes, com objetivo de torna-los obedientes e dóceis.

A disciplina se exerce como um "poder relacional que se autossustenta por seus próprios mecanismos". (FOUCAULT, 2014b, p. 174). O castigo praticado na cena, com retirada de sala e a condução para o exame, ou seja, a ação de conduzir o estudante para o inquérito que visa 
trazer a verdade sobre o que aconteceu é parte desse processo de disciplinarização e de um exercício de poder. A cena que assistimos seria uma forma de ação do poder disciplinar sobre o estudante em questão. O indivíduo como o átomo fictício de uma representação "ideológica" da sociedade; mas é também uma realidade fabricada por essa tecnologia específica de poder que se chama a "disciplina” (FOUCAULT, 2014b, p. 189).

Esse acontecimento aponta para a produção desse sujeito entre discursos e práticas de poder, as quais o anunciam e produzem como um indivíduo problemático, como a vice-diretora disse em nosso primeiro encontro. Cabe agora questionar se o motivo para a percepção desse sujeito como um problema está atravessado pela sua homossexualidade. Dito de outra forma, o que torna esse menino um "problema" para a escola é o fato dele não esconder sua homossexualidade? Seria isso que a vice-diretora estava dizendo quando disse que havia um grupo de meninos gostava de chamar a atenção?

Sobre esse episódio podemos lançar três considerações: (i) ele anuncia a escola enquanto uma organização produtora de disciplinas e estruturada em mecanismos que produzem corpos a partir do exercício do poder disciplinar; (ii) a dimensão do cuidado como forma de legitimação de modelo disciplinar que se utiliza da hierarquia e dos processos de castigo e exame, para conduzir aqueles que são considerados como desviantes para processos de disciplinarização; (iii) a normalização das sexualidades presente no espaço escolar, que apresenta os estudantes homossexuais como "problemas" a serem tratados pela instituição. Sendo assim, a escola pratica mecanismos de disciplinarização que visam à homogeneização das estudantes através do silenciamento/negação dos conflitos, porém resguardando as individualidades para o momento do exame e da punição regulatória. A noção de normalidade cumpre a função de estabelecer os princípios da coerção, pois à medida que definimos a norma, construímos os limites e as medidas para examinar os desvios (FOUCAULT, 2014b).

Numa proposta de reflexão mais abrangente trabalhamos com o conflito como um produto da diferença. No ambiente escolar o conflito é um mensurador do clima escolar. Em geral as causas dos conflitos são variadas, podem estar associadas à falha na comunicação, a dificuldade de diálogo entre as partes devido as divergências de interpretações e até mesmo ao excesso de normas disciplinares (nesse caso o conflito pode se transformar em um comportamento indisciplinado).

Todavia, o que mais dificulta a administração de conflitos escolares é identificar as circunstâncias produtoras dos conflitos, sendo assim insuficiente compreender a motivação, pois quando está aparece o conflito já está configurado. O que estamos chamando de 
circunstâncias constitui um conjunto de fatores, como o espaço da escola onde o conflito ocorreu, as características dos sujeitos envolvidos, as disputas de poder, as atividades praticadas, e principalmente a origem das primeiras divergências. Essas circunstâncias são por nós ignoradas tanto na escola como na vida cotidiana. Só percebemos o conflito quando ele já se configurou em formas de violência, por essa razão, há no senso comum identificação do conflito como uma violência. No entanto, o sintoma de quando o conflito se transforma em atos de agressão e violência é o indicador de que nós falhamos enquanto comunidade escolar e sociedade em identificar suas circunstâncias propulsoras, e nesse momento temos a tendência a resolver esse conflito que se transformou em violência, através de outras formas de violência física e/ou simbólica.

Em diálogo com autores que conceituam a violência, Longo (2017) propõe pensarmos a violência para além dos grandes episódios que rompem com a rotina escolar e adquirem peso e visibilidade midiática. A autora entende a violência escolar enquanto parte de processos que se exercem no cotidiano, pautados numa concepção de estudante padronizada, sendo assim, aquelas que fogem a esse norte acabam sendo enxergadas como diferentes. Sendo esta diferença, vista como uma questão a ser resolvida e/ou sanada.

As possibilidades de a violência refletir um hiato entre os alunos reais que chegam hoje à escola com suas diferenças de cor, raça, etnia, gênero, orientação sexual e outros marcadores identitários e os protótipos modernos de aluno padrão homogêneo produzidos segundo uma lógica etnocentricamente determinada (LONGO, 2017, p. 714).

Longo (2017) assinala que enquanto educadores e teóricos da educação faz-se necessário um olhar atento para os pequenos acontecimentos presentes no cotidiano, e nos mecanismos pelos quais as violências se tornam invisíveis. A autora ressalta ainda, o quanto a violência simbólica é exercida cotidianamente. Por esse caminho, refazemos alguns questionamentos: o que significa a cena narrada? O que o grito representa no cotidiano da escola? Qual o lugar das homossexualidades na escola? Quem são os sujeitos considerados como legítimos dentro do espaço escolar? Como possibilitar trocas entre estudantes, docentes, gestão e equipe escolar que não sejam pautados na padronização dos sujeitos?

Se entendermos o grito como parte do processo de exercício da disciplina sobre aquele sujeito, aquela cena nos convida a pensar que esse processo se faz por meio de ações e mecanismos de violências simbólicas. O menino homossexual interpelado, tirado de sala pelo inspetor durante a aplicação do questionário é este sujeito diferente que excede os padrões e as expectativas do que a escola tradicionalmente espera. Essa cena é parte do ato de constituição 
do sujeito, ela diz da forma como esse menino está sendo ensinado, normalizado, disciplinado, corrigido pela instituição escolar.

“(...) o reconhecimento de si acontece, de modo que o que posso "ser", de maneira bem literal, é limitado de antemão por um regime de verdade que decide quais formas de ser serão reconhecíveis e não reconhecíveis e de que maneira esse processo será determinado" (BUTLER, 2015, p. 35).

Ele não é o modelo, ele tido como aquele que quer chamar atenção, ele é visto como o sujeito que causa problemas na escola. Era esse discurso que anunciava esse menino, mesmo antes de conhecê-lo. Já o conhecíamos pelo relato produzido sobre ele, como sujeito perigoso e desviante. Ele era o problema, mesmo antes da cena acontecer. Ele era questão mesmo antes de conhecê-lo, ele estava presente desde nossa primeira entrada na escola, através dos discursos que eram produzidos sobre ele.

Assim, entender os mecanismos pelos quais as violências simbólicas se constituem na escola, passa fundamentalmente por uma investigação arqueológica das instâncias de poder, pelos discursos e saberes que são produzidos dentro das relações entre os sujeitos no espaço escolar.

\section{Algumas considerações não conclusivas}

Resgatamos aqui o convite feito na introdução. Desnaturalizar e desconstruir a eternização da escola, olhar a escola como uma instituição que surgiu em um contexto de disciplinarização das massas para que estas estivessem preparadas e domesticadas para o mercado de trabalho. Esse projeto político de escolarização reforçou durante décadas a indisciplina como desrespeito às ordens e o conflito como violência. Nosso convite é compreender as duas cenas problematizadas pelo viés da reivindicação de estudantes que não aceitam mais esse projeto de escola.

É através dos conflitos escolares que as relações intersubjetivas são construídas e fortalecidas. Os conflitos ajudam os estudantes a enxergar o mundo pela perspectiva do outro, pelo viés da diferença, pela alteridade. Racionalizam as estratégias de competência e cooperação, possibilitam a construção do diálogo, e principalmente, ensinam que a controvérsia é uma fonte de crescimento e de amadurecimento social.

Assim, além dos conflitos escolares, as cenas analisadas nesse ensaio apontam para a escola enquanto espaço de produção de subjetividades. Os conflitos narrados neste artigo apontam o quanto o cotidiano escolar ainda se revela marcado pelo cerceamento das subjetividades, nos seguintes aspectos: (i) nossas cenas abordam o quanto ainda é difícil habitar 
os espaços escolares quando não a sua subjetividade não se enquadra no ideal normalizado; (ii) nas cenas ficam expostas ação do poder disciplinar, investido em práticas de sanções/punições, negações/silenciamentos frente aos temas da diversidade; (iii) na cena dois, há uma conexão entre cuidado e disciplina, expressa na fala da gestão da escola, entretanto a dimensão do cuidado se perde na dinâmica escolar; (iv) ainda na cena dois, encontramos indícios que apontam para a naturalização de práticas de violências simbólicas no cotidiano escolar, o grito e a retirada de sala sem explicações, refletem essa naturalização; $(v)$ a anunciação da homossexualidade como desvio e como um problema a ser corrigido.

Indo além das interdições e silenciamentos que envolvem as duas cenas, torna-se essencial pensar como que estes episódios, dizem sobre a forma como as subjetividades consideradas desviantes, abjetas são tratadas e contidas no espaço escolar. Seguindo uma inspiração foucaultiana é preciso:

(...) levar em consideração o fato de se falar de sexo, quem fala, os lugares e os pontos de vista de que se fala, as instituições que o incitam a fazê-lo, que armazenam e difundem o que dele se diz, em suma, o "fato discursivo" global, a "colocação do sexo em discurso" (FOUCAULT, 2013, p. 18).

Dessa forma, analisando a escola como instituição que atua na impressão de um discurso acerca do sexo, interessa-nos perceber por entre as cenas como esse discurso atua, e, como ele encontra resistências mobilizadas pela própria condição de existência do menino naquele contexto. Apesar de sua sexualidade ser trabalhada na fala da vice-diretora como um problema, um menino não se escondia, não aceitava ocupar cantos escuros, o menino resistia dentro do espaço escolar, marcando a tensão existente naquele ambiente entre sua existência e sua condição abjeta. A atuação desse menino dentro do seu contexto abre e reforça a importância de acreditarmos na possibilidade da escola. O cotidiano pode se constituir em novos espaços para a produção de novas subjetividades, pautadas não mais na produção de corpos disciplinarizados pela instituição escolar, mas como lugar potencializador da diferença e problematizador das estruturas. Escola como espaço da problematização num sentido foucaultiano, "da elaboração de um domínio de fatos, práticas e pensamentos” (FOUCAULT, 2014a, p. 222) que lançam problemas a serem debatidos dentro e fora da instituição escolar. problematização como um caminho reflexivo que indaga a realidade e os sujeitos ao redor.

\section{Referências}


ANDRADE, Marcelo. Conversa com o educador Marcelo Andrade. Revista Multidisciplinar de Ensino, Pesquisa, Extensão e Cultura do Instituto de Aplicação Fernando Rodrigues da Silveira (CAp-UERJ), v. 5, n. 19, p. 2-10, 2016.

; CÂMARA, Luiz. Diferenças silenciadas e diálogos possíveis: a pesquisa em educação como superação de silenciamentos. In: ANDRADE, Marcelo (org). Diferenças silenciadas: pesquisas em educação, preconceitos e discriminações. Rio de Janeiro: 7Letras, 2015.

ARIÈS, Phillipe. História social da infância e da família. Tradução: D. Flaksman. Rio de Janeiro: LCT, 1978.

BONDÍA, Jorge Larossa. Notas sobre a experiência e o saber da experiência. Revista Brasileira de Educação, Rio de Janeiro, v. Jan/Fev/Mar/Abr, n.19, 2002.

BUTLER, Judith. Corpos que pesam: sobre os limites discursivos do "sexo". In: LOURO, Guacira Lopes. O corpo educado: pedagogias sexualidades. Belo Horizonte: Autêntica, 2000. 2015 . Relatar a si mesmo: crítica da violência ética. Belo Horizonte: Autência Editora,

CANDAU, Vera. Diferenças culturais, interculturalidade e educação em direitos humanos. Educação \& Sociedade, Campinas, v. 33, n. 118, p. 235-250, 2012.

COSTA, Jurandir Freire. A devoração da esperança no próximo. Folha de S. Paulo. Caderno Mais!, p.8, 1998.

CUNHA, Marcela. B.; COSTA, Márcio. O clima escolar de escolas de alto e baixo prestigio. In: Reunião da Associação Nacional de Pós-Graduação e Pesquisa em Educação, 32., Anais... 2009, Caxambu-MG. Sociedade, cultura e educação: novas regulações, 2009.

FERRARI, Anderson. Silêncio e silenciamentos: em torno das homossexualidades masculinas. In: Silêncios e Educação. Juiz de Fora: Ed. UFJF, 2011.

; MARQUES, Luciana. Silêncios e Educação. In: Silêncios e Educação. Juiz de Fora: Ed. UFJF, 2011.

FOUCAULT, Michel. História da Sexualidade I: A vontade de saber. Rio de Janeiro: Edições Graal, 2013. Universitária, 2014a.

Ditos \& Escritos V: Ética, Sexualidade e Política. Rio de Janeiro: Forense Vigiar e punir: nascimento da prisão. Petrópolis: RJ, Vozes, 2014b.

JUNQUEIRA, Rogério. Pedagogia do armário: a normatividade em ação. Revista Retratos da Escola, Brasília, v. 7, n. 13, p. 481-498, jul./dez. 2013.

LAZZARTO, Maurizio. Biopolítica/bioeconomia. In: PASSOS, Izabel. Poder, normalização e violência: incursões foucaultianas para a atualidade. Belo Horizonte: autêntica Editora, 2013. 
LONGO, Monique Marques. "É bem raro encontrar alunos violentos entre aqueles que acham sentido e prazer na escola": a violência escolar entre discursos e conceitos. Revista Contrapontos - Eletrônica, vol. 17 - n. 4 - Itajaí, out-dez 2017.

VARELA, Júlia e ALVAREZ-URIA, Fernando. Arqueologia de la escuela. Madrid. Espanha: Ediciones La Piqueta, 1993.

${ }^{\text {i }}$ Pesquisa coordenada pelo Prof. Marcelo Andrade da PUC-Rio, contou com a participação de uma equipe de pesquisadores pertencentes às seguintes universidades: PUC-Rio; UERJ; UERJ/FFP; UNIRIO; e, UFRJ.

ii Optamos por não criar nomes fictícios para a Diretora, uma vez que ela será a única citada com este cargo neste ensaio. 